\title{
Comparative study on wheel-rail dynamic interactions of side-frame cross-bracing bogie and sub-frame radial bogie
}

\author{
Chunlei Yang $\cdot$ Fu Li $\cdot$ Yunhua Huang $\cdot$ \\ Kaiyun Wang $\cdot$ Baiqian He
}

Received: 12 July 2012/Revised: 29 December 2012/Accepted: 7 January 2013/Published online: 5 June 2013

(C) The Author(s) 2013. This article is published with open access at Springerlink.com

\begin{abstract}
Improving freight axle load is the most effective method to improve railway freight capability; based on the imported technologies of railway freight bogie, the $27 \mathrm{t}$ axle load side-frame cross-bracing bogie and sub-frame radial bogie are developed in China. In order to analyze and compare dynamic interactions of the two newly developed heavy-haul freight bogies, we establish a vehicle-track coupling dynamic model and use numerical calculation methods for computer simulation. The dynamic performances of the two bogies are simulated separately at various conditions. The results show that at the dipped joint and straight line running conditions, the wheel-rail dynamic interactions of both bogies are basically the same, but at the curve negotiation condition, the wear and the lateral force of the side-frame cross-bracing bogie are much higher than that of the sub-frame radial bogie, and the advantages become more obvious when the curve radius is smaller. The results also indicate that the subframe radial bogie has better low-wheel-rail interaction characteristics.
\end{abstract}

C. Yang $\cdot$ F. Li $\cdot$ Y. Huang

School of Mechanical Engineering, Southwest Jiaotong

University, Chengdu 610031, China

\section{Yang $(\bowtie)$}

Department of Product Development, CSR Meishan Company

Limited, Meishan 620032, China

e-mail: yclei2000@163.com

K. Wang · B. He

State Key Laboratory of Traction Power, Southwest Jiaotong University, Chengdu 610031, China
Keywords Heavy haul - Side-frame cross-bracing bogie . Sub-frame radial bogie . Wheel-rail dynamic interaction

\section{Introduction}

With its comprehensive advantages such as the large transport capacity, low energy consumption, light pollution, less occupation of the land, and high safety, the railway heavy-haul transport has developed rapidly all over the world. The side-frame cross-bracing bogie [1-3] and sub-frame radial bogie [4-9] are both main freight bogies applied in railway heavy-haul transport. In order to meet the needs of development of the Chinese railway transportation, the key technologies of both bogies were imported [10]; since then, many engineers and researchers in China began to study and investigate the technologies of the two bogies [11-26] and successfully developed a $25 \mathrm{t}$ axle load side-frame cross-bracing bogie named K6 [11] and a sub-frame radial bogie named K7 [24] to meet the needs of Datong-Qinhuangdao coal transportation.

In recent years, $27 \mathrm{t}$ axle load side-frame cross-bracing bogie (Fig. 1) and sub-frame radial bogie (Fig. 2) were developed in China to further enhance the railway transport capacity. The two bogies mainly consist of three parts, the bolster, the wheel sets, and the side-frame. The main difference of the two bogies is in the side-frame. The former uses an elastic crossing bar to connect the left and the right side-frame, while the latter uses a sub-frame radial appliance to connect the front and the rear wheel sets. In this paper, the dynamic performances of the two bogies are analyzed and compared at various conditions based on the theory of vehicle-track coupling dynamics [27] and a vehicle-track coupling dynamic model [28] in order to find which bogie has better low-wheel-rail dynamic interaction 


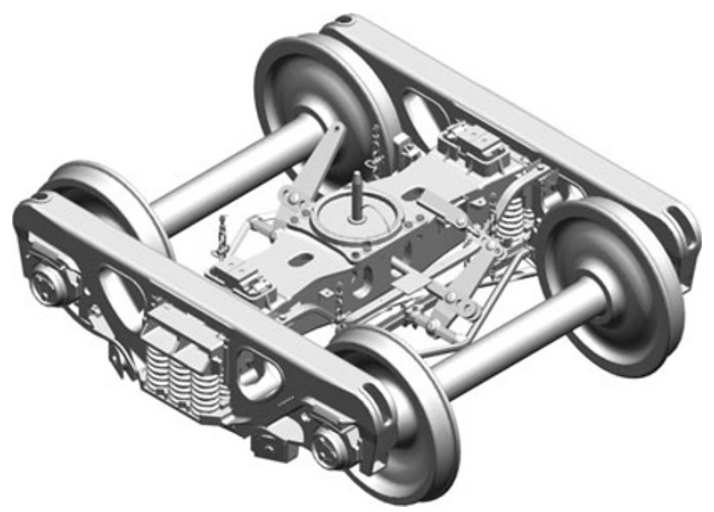

Fig. 127 t Side-frame cross-bracing bogie

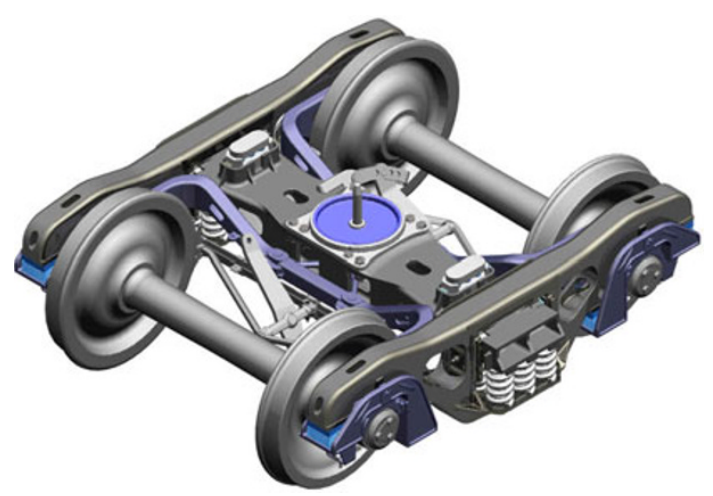

Fig. 227 t Sub-frame radial bogie

characteristics. The main parameters of the two bogies are shown in Table 1.

\section{Vehicle-track coupling dynamic model and various calculation conditions}

A vehicle-track coupling dynamic model is established according to the structural characteristics of the bogie. The degrees of freedom (DOFs) of the vehicle and track parts as well as the non-linear characteristics such as wheel-rail contact geometry, wheel-rail normal force, and wheel-rail

Table 1 Main parameters of the two bogies

\begin{tabular}{lllll}
\hline Bogie type & $\begin{array}{l}\text { Tare } \\
\text { weight } \\
(\mathrm{kg})\end{array}$ & $\begin{array}{l}\text { Wheelbase } \\
(\mathrm{mm})\end{array}$ & $\begin{array}{l}\text { Primary } \\
\text { vertical } \\
\text { stiffness } \\
\left(\mathrm{MN} \cdot \mathrm{m}^{-1}\right)\end{array}$ & $\begin{array}{l}\text { Primary } \\
\text { lateral } \\
\text { stiffness } \\
\left(\mathrm{MN} \cdot \mathrm{m}^{-1}\right)\end{array}$ \\
\hline $\begin{array}{c}\text { Side-frame cross- } \\
\text { bracing bogie }\end{array}$ & 4,730 & 1,830 & $150-200$ & $10-14$ \\
$\begin{array}{c}\text { Sub-frame radial } \\
\text { bogie }\end{array}$ & 4,850 & 1,800 & $25-50$ & $2.5-5$ \\
\hline
\end{tabular}

tangential creep force are all taken into account in the vehicle-track system. In addition, the elastic cross-bracing bar of the side-frame cross-bracing bogie and the subframe radial appliance of the sub-frame radial bogie are simplified as three-directional stiffness separately in the model. The vehicle-track dynamic model is a complex and huge dynamic system as shown in Fig. 3 and the DOFs of the whole dynamic system are shown in Table 2. More details about Fig. 3 and Table 2 can be found in the reference [27].

In order to compare and analyze the wheel-rail interaction characteristics of the two bogies in various simulation conditions, we consider three scenarios: dipped rail joint, linear railway, and curve line. The detailed calculation conditions are shown in Table 3.

\section{Analysis and comparison of wheel-rail dynamic interaction}

\subsection{Wheel-rail interaction at impulsive excitation}

Figure 4 shows the wheel-rail dynamic response comparisons of a heavy-haul freight car equipped with the sideframe cross-bracing bogie and the sub-frame radial bogie passing through the dipped joint at a speed of $80 \mathrm{~km} / \mathrm{h}$. In Fig. 4, we can see that the diagrams of the wheel-rail dynamic interaction of both the bogies are basically the same and the amplitudes have little difference. Relatively, the wheel-rail vertical force (Fig. 4a) and the vertical displacements of rail substructures (Fig. $4 \mathrm{~d}-\mathrm{f}$ ) of the subframe radial bogie are slightly larger (about $2 \%$ ) than that of the side-frame cross-bracing bogie. That is because the sub-frame radial appliance is much heavier than that of the crossing bar, which increases the unsprung mass of the bogie. Therefore, to reduce wheel-rail dynamic interactions, the sub-frame radial bogie should be lightened as much as possible.

\subsection{Wheel-rail interaction at random excitation on straight line}

Figure 5 shows the mean values of the wheel-rail vertical force, wheel-rail wear, and wheel-rail contact stress response as the heavy-haul freight car runs on the straight line at the speed of 80,100 , and $120 \mathrm{~km} / \mathrm{h}$, where the Chinese three-mainline spectrum excitation is considered. One can see that the mean values of the wheel-rail responses of the two bogies almost have no changes with speed variation, and the wheel-rail dynamic interactions of both bogies are basically the same. 
(a)

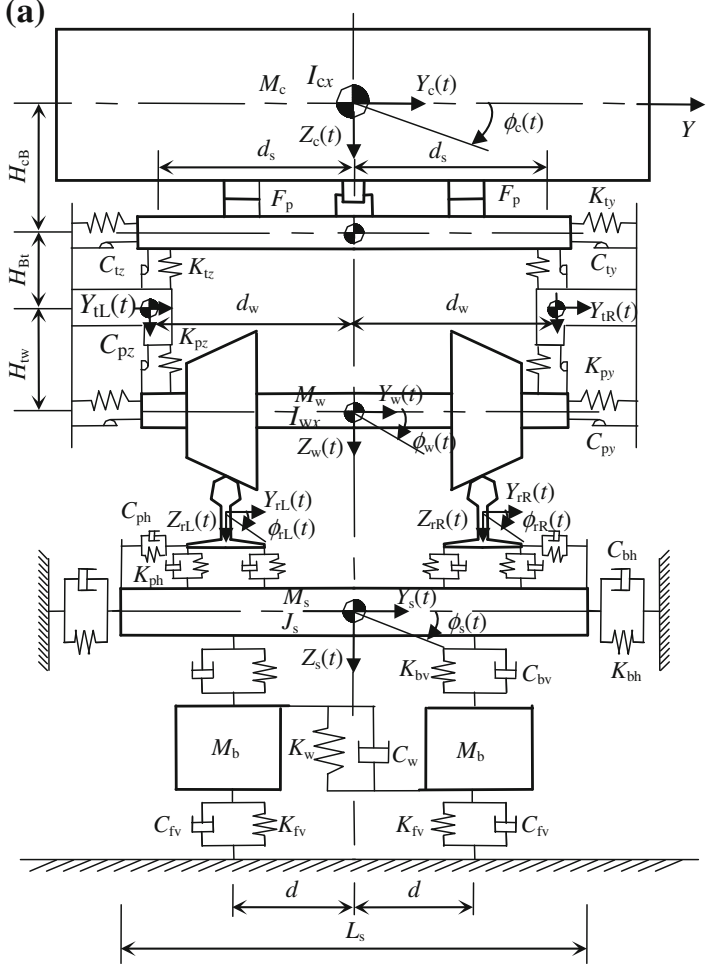

(b)

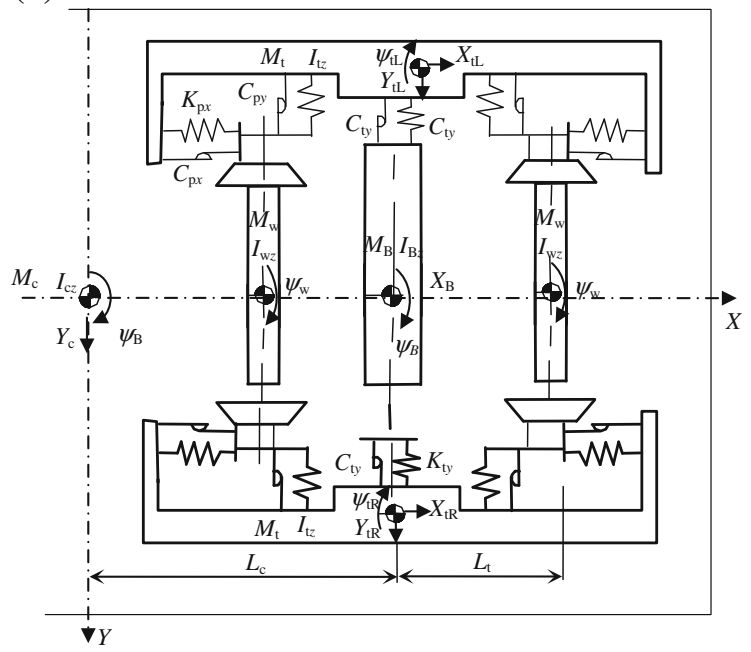

Fig. 3 Vehicle-track coupling dynamic model. a End view. b Top view

Table 2 DOFs of the vehicle-track coupling dynamic model

\begin{tabular}{lllllll}
\hline Freedom & Longitudinal & Lateral & Vertical & Rolling & Yawing & Pitching \\
\hline Car body & $X_{\mathrm{c}}$ & $Y_{\mathrm{c}}$ & $Z_{\mathrm{c}}$ & $\varphi_{\mathrm{c}}$ & $\psi_{\mathrm{c}}$ & $\beta_{\mathrm{c}}$ \\
Bolster $(i=1,2)$ & $X_{\mathrm{B} i}$ & $Y_{\mathrm{B} i}$ & $Z_{\mathrm{B} i}$ & $\varphi_{\mathrm{B} i}$ & $\psi_{\mathrm{B} i}$ & $\psi_{\mathrm{t}(\mathrm{L}, \mathrm{R}) i}$ \\
Side-frame $(i=1,2)$ & $X_{\mathrm{t}(\mathrm{L}, \mathrm{R}) i}$ & $Y_{\mathrm{t}(\mathrm{L}, \mathrm{R}) i}$ & $Z_{\mathrm{t}(\mathrm{L}, \mathrm{R}) i}$ & - & $\psi_{\mathrm{w} i}$ & - \\
Wheel set $(i=1-4)$ & - & $Y_{\mathrm{w} i}$ & $Z_{\mathrm{w} i}$ & $\varphi_{\mathrm{w} i}$ & - \\
Rail & - & $Y_{\mathrm{r}(\mathrm{L}, \mathrm{R})}$ & $Z_{\mathrm{r}(\mathrm{L}, \mathrm{R})}$ & $\varphi_{\mathrm{r}(\mathrm{L}, \mathrm{R})}$ & - \\
Sleeper & - & $Y_{\mathrm{s} i}$ & $Z_{\mathrm{s}}$ & $\varphi_{\mathrm{s}}$ & - & - \\
Ballast & - & - & $Z_{\mathrm{b}(\mathrm{L}, \mathrm{R})}$ & - & & - \\
\hline
\end{tabular}

Table 3 Calculation conditions

\begin{tabular}{|c|c|c|c|}
\hline Serial number & Railway & Excitation & Speed $(\mathrm{km} / \mathrm{m})$ \\
\hline 1 & Linear railway line & Dipped rail joint & 80 \\
\hline 2 & Linear railway line & $\begin{array}{l}\text { Chinese three-mainline track } \\
\text { spectrum }\end{array}$ & 80,100 , and 120 \\
\hline 3 & Curve railway line of $R=300 \mathrm{~m}$ & Without track irregularity & 55 \\
\hline 4 & Curve railway line of $R=300 \mathrm{~m}$ & $\begin{array}{l}\text { Chinese three-mainline track } \\
\text { spectrum }\end{array}$ & 55 \\
\hline
\end{tabular}

\subsection{Wheel-rail interaction on curve negotiation}

Figure 6 shows the wheel-rail lateral force and the wheelrail wear power of the external side wheel of the two bogies as the vehicle passes through a smooth curve at a speed of $55 \mathrm{~km} / \mathrm{h}$; the curve radius is $300 \mathrm{~m}$. In Fig. 6, we can see that the wheel-rail lateral force and wheel-rail wear power of the side-frame cross-bracing bogie are apparently much higher than those of the sub-frame radial bogie. For example, the maximum wheel-rail lateral force of the side-frame crossbracing bogie is $28.16 \mathrm{kN}$, while that of the sub-frame radial bogie is $15.68 \mathrm{kN}$. The former is about 1.8 times larger than the latter. The maximum wheel-rail wear power of the sideframe cross-bracing bogie is $88.89 \mathrm{Nm} \cdot \mathrm{m}^{-1}$, while that of 
(a)

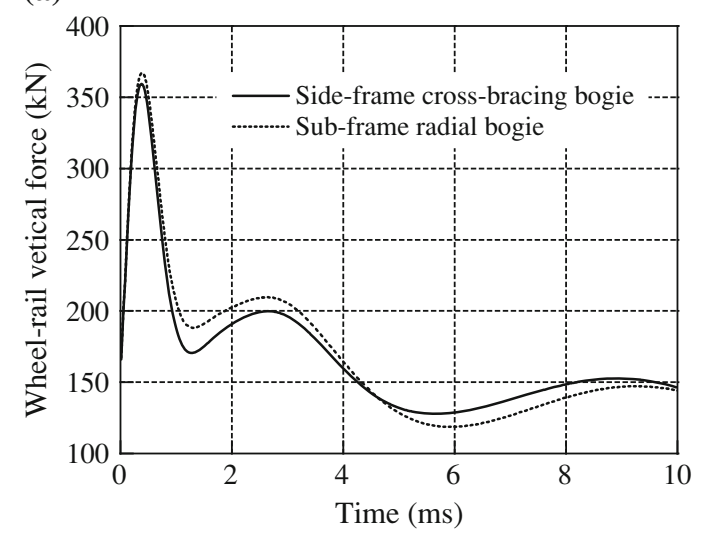

(c)

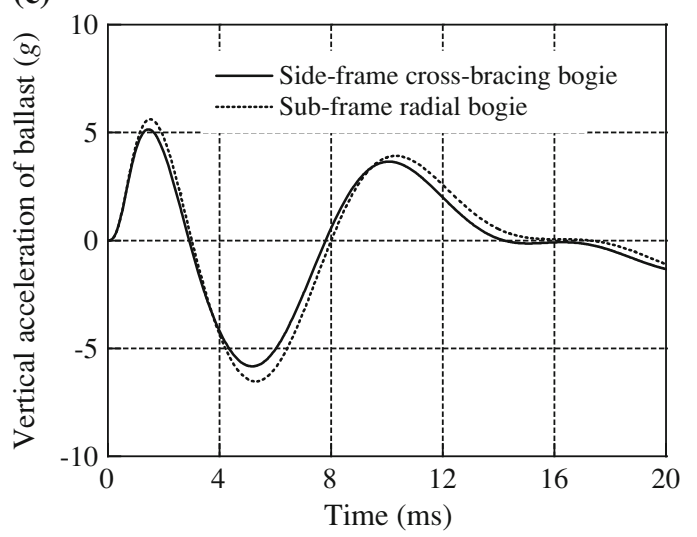

(e)

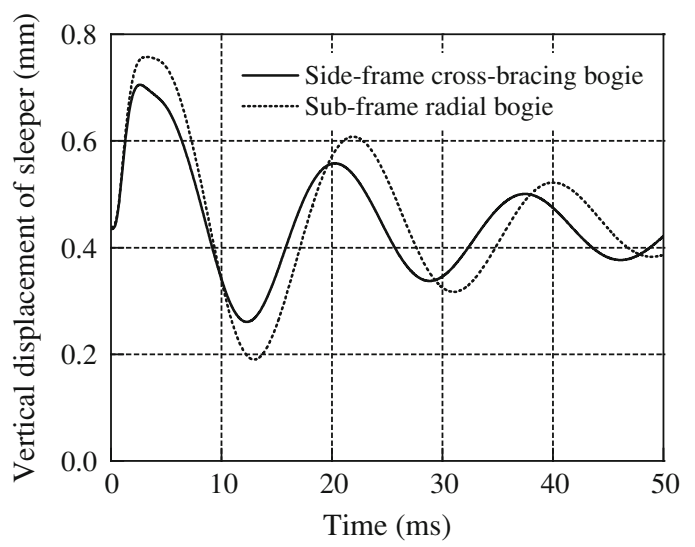

(b)

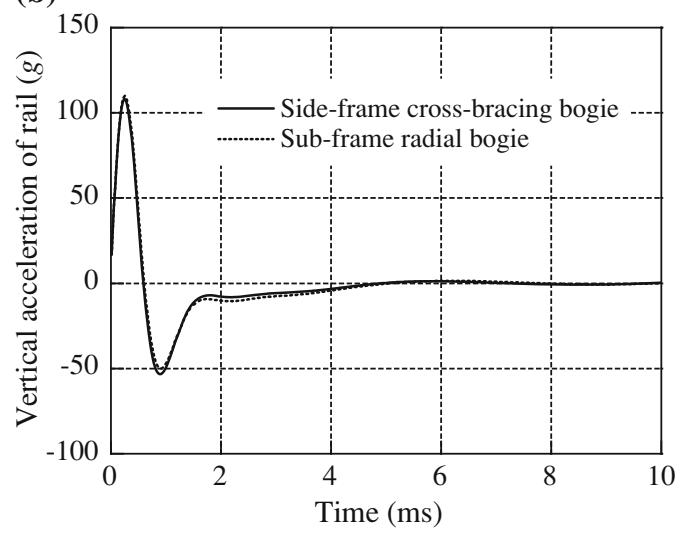

(d)

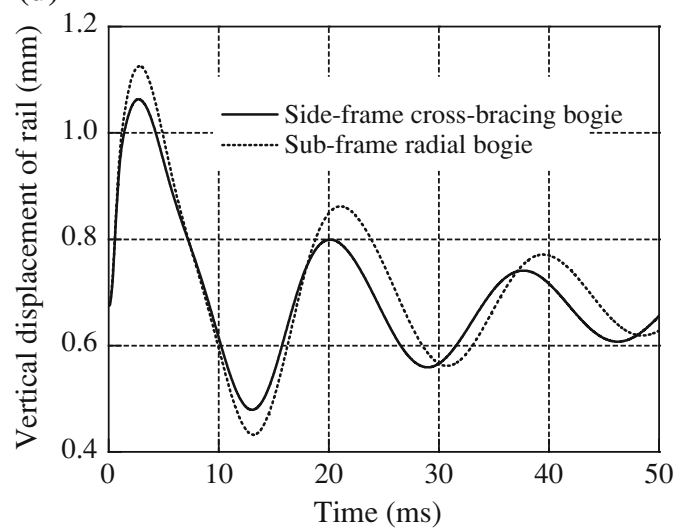

(f)

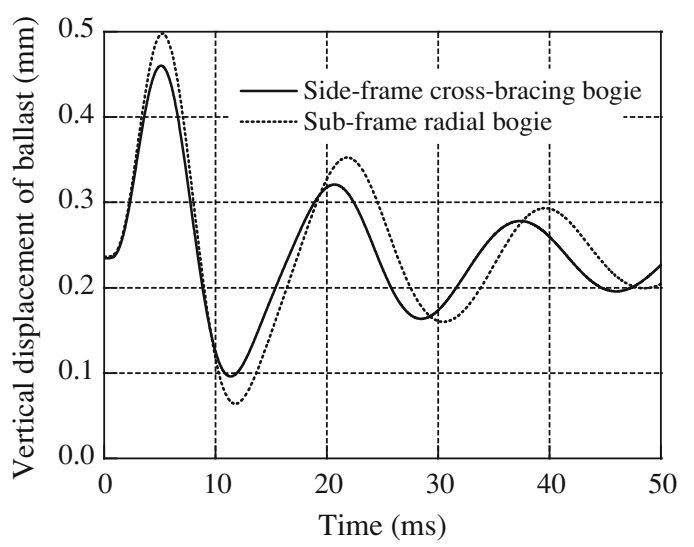

Fig. 4 Wheel-rail dynamic interactions of the two bogies at impulsive excitation. a Wheel-rail vertical force. b Vertical acceleration of rail. c Vertical acceleration of ballast. d Vertical displacement of rail. e Vertical displacement of sleeper. f Vertical displacement of ballast

the sub-frame radial bogie is $30.16 \mathrm{Nm} \cdot \mathrm{m}^{-1}$, which is about 2.95 times than the former. These indicate that the sub-frame radial bogie can reduce the wheel-rail lateral interactions and can particularly reduce the wheel-rail wear significantly when negotiating a curve.

Figure 7 shows the diagrams of the wheel-rail lateral force of the four wheel sets. Seen from the figure, the values of the four wheel sets of the side-frame cross- bracing bogie are very uneven. The maximum value of the first and the third wheel set is nearly 3 times greater than that of the second and the fourth wheel set; this means the guiding wheel sets will wear more quickly than that of the non-guiding wheel sets and cause the guiding wheel sets to repair and change, or even scrapped in advance. But, for sub-frame radial bogie, the values of the four wheel sets are basically the same, and the maximum is also much lower 
(a)

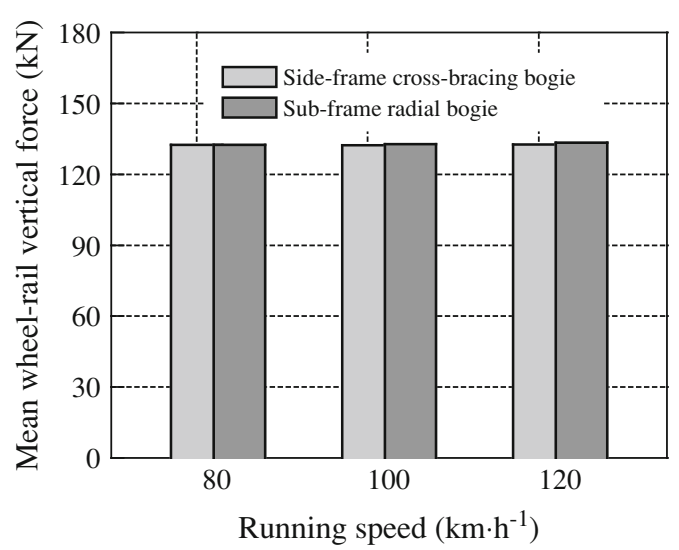

(c)

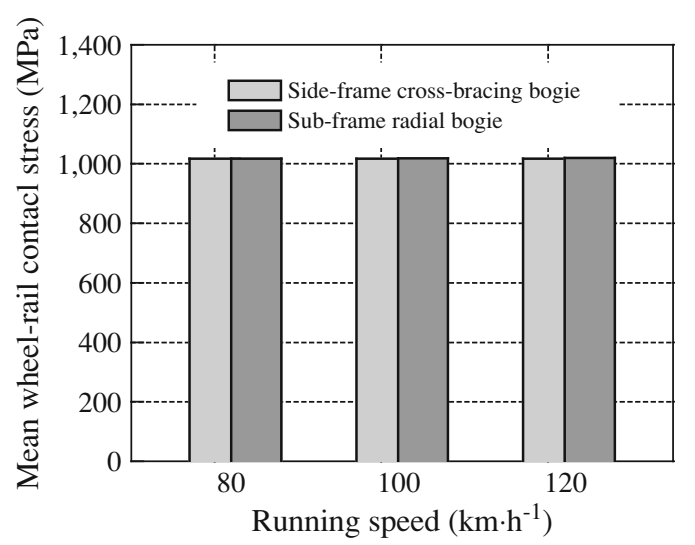

(b)

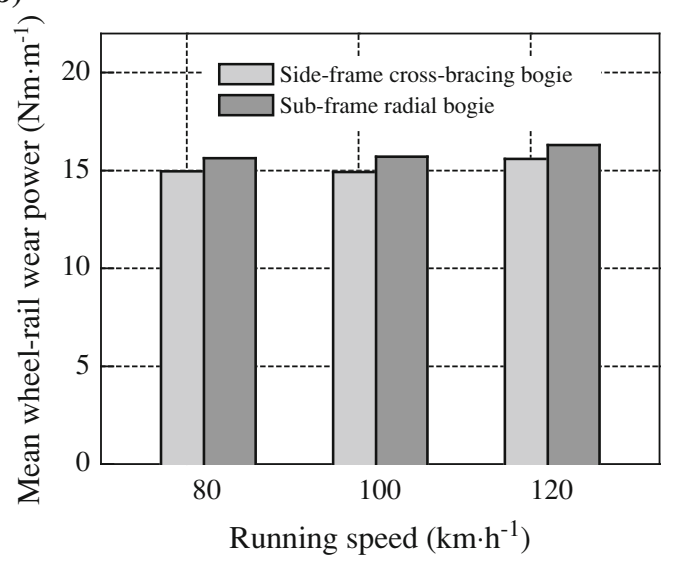

Fig. 5 Wheel-rail dynamic interactions of the two bogies with random excitation on straight line. a Mean wheel-rail vertical force. b Mean wheel-rail wear power. c Mean wheel-rail contact stress

(a)

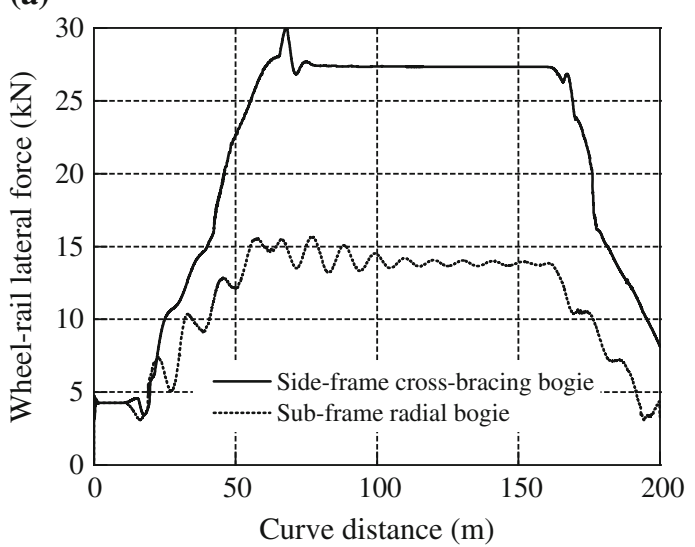

(b)

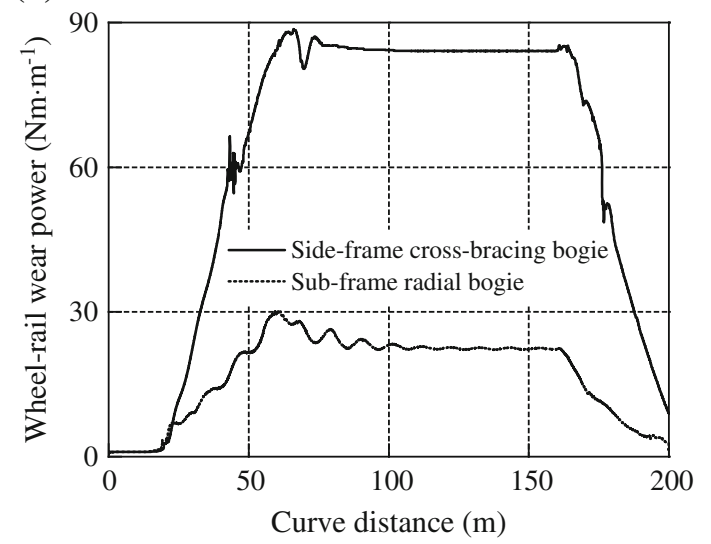

Fig. 6 Wheel-rail dynamic interactions of the two bogies negotiating without excitation. a Wheel-rail lateral force. b Wheel-rail wear power

than that of the side-frame cross-bracing bogie; so relatively, the wheel-rail wear would be reduced and the life of the wheel set would be extended.

Figure 8 shows the comparison of the peak values of the wheel-rail lateral force and the wheel-rail wear power as the vehicle passes through smooth curved lines with different radii. As shown from Fig. 8, the peak values of the wheel-rail lateral force and the wheel-rail wear power of the side-frame cross-bracing bogie are significantly larger than those of the sub-frame radial bogie, and the difference 
(a)

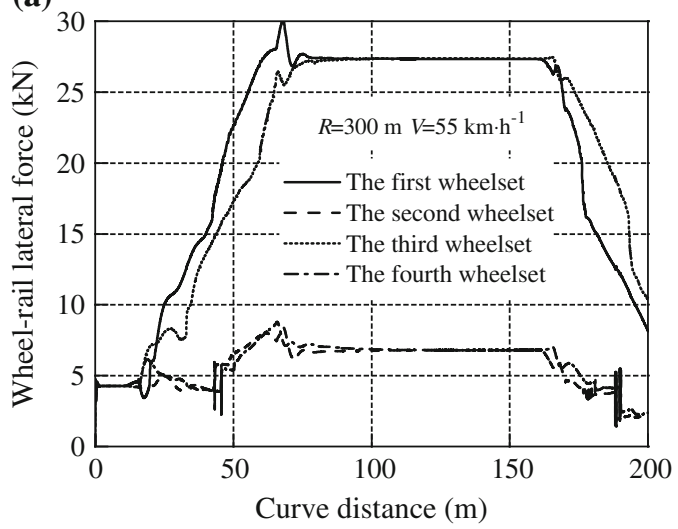

(b)

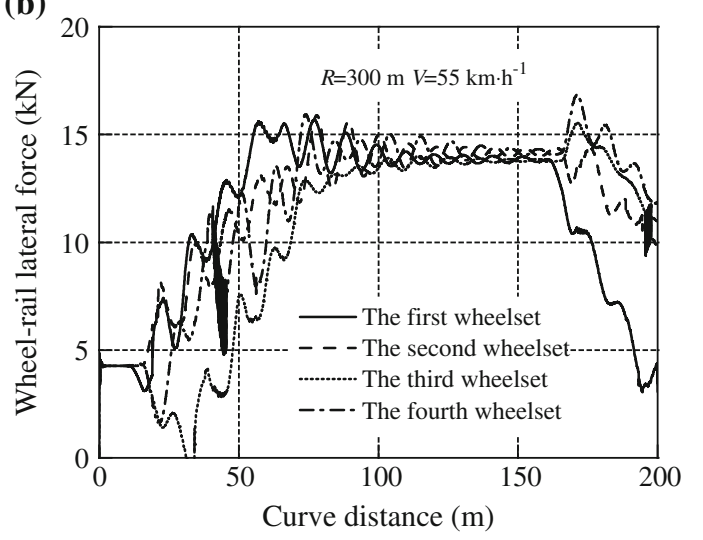

Fig. 7 Wheel-rail lateral forces of different wheel sets while negotiating without excitation. a Side-frame cross-bracing bogie. b Sub-frame radial bogie
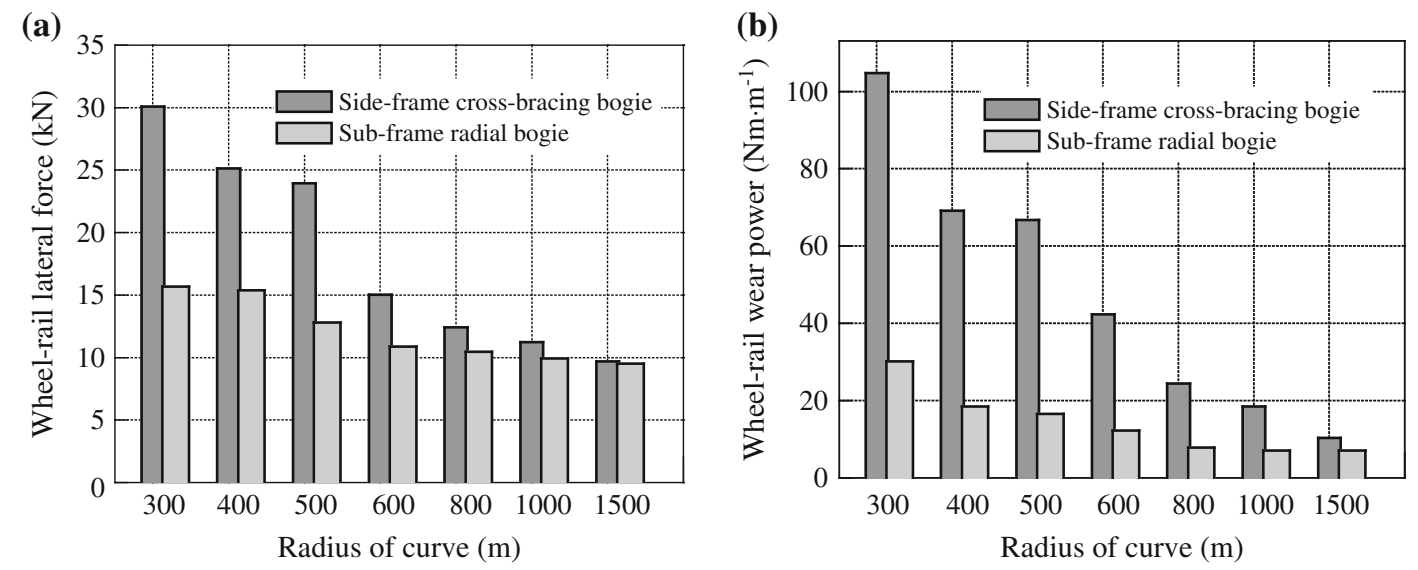

Fig. 8 Peak values of wheel-rail dynamic interaction of the two bogies. a Wheel-rail lateral force. b Wheel-rail wear power

becomes gradually larger with the reduction of the radius. For instance, when the radius is $1,500 \mathrm{~m}$, both the bogies have little difference; when the radius is $1,000 \mathrm{~m}$, the peak value of the wheel-rail lateral force and wheel-rail wear power of the side-frame cross-bracing bogie is, respectively, $11.24 \mathrm{kN}$ and $18.44 \mathrm{Nm} \cdot \mathrm{m}^{-1}$, while that of the subframe radial bogie is correspondingly $8.3 \mathrm{kN}$ and $7.1 \mathrm{Nm} \cdot \mathrm{m}^{-1}$, the former being about 1.35 times and 2.6 times larger than the latter, respectively. As the curve radius is $300 \mathrm{~m}$, the peak values of the former are, respectively, $28.16 \mathrm{kN}$ and $104.7 \mathrm{Nm} \cdot \mathrm{m}^{-1}$, while that of the latter are $15.68 \mathrm{kN}$ and $30.16 \mathrm{Nm} \cdot \mathrm{m}^{-1}$, respectively, the former being about 1.8 times and 3.47 times larger than the latter, respectively.

Figure 9 shows the comparison of the mean values of wheel-rail lateral force and wheel-rail wear power as the vehicle passes through curved lines of different radii, where Chinese three-mainline spectra as the random excitation is considered. Seen from the figure, regardless of whether the mean value of the wheel-rail lateral force or the wheel-rail wear power, the values of the side-frame cross-bracing bogie are always higher than those of the sub-frame radial bogie; and, the smaller the curve radius, the greater the difference. Only when the curve radius is beyond $1,000 \mathrm{~m}$ do the mean values of the wheel-rail lateral force and the wheel-rail wear power of both bogies tend to be the same.

\subsection{Actual wheel-rail wear comparison between two types of bogies}

The $25 \mathrm{t}$ axle load side-frame cross-bracing bogie named $\mathrm{K} 6$ and the $25 \mathrm{t}$ axle load sub-frame radial bogie named $\mathrm{K} 7$ have been used on Datong-qinghuangdao heavy-haul line for about $2 \times 10^{5} \mathrm{~km}$. Figure 10 shows the difference of the flange wear of the different bogies. One can see from the figure that the mean value of the flange wear of the K6-type bogie is $0.52 \mathrm{~mm}$, while that of the K7-type bogie is $0.15 \mathrm{~mm}$, less than one-third of the K6-type bogie. The 
(a)

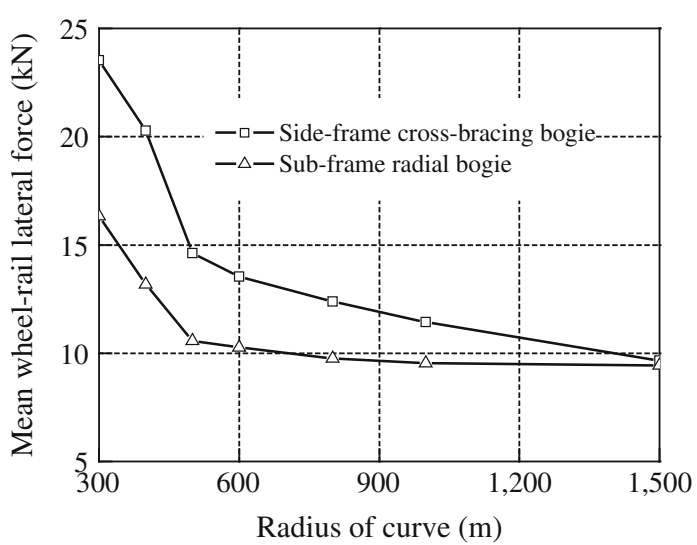

(b)

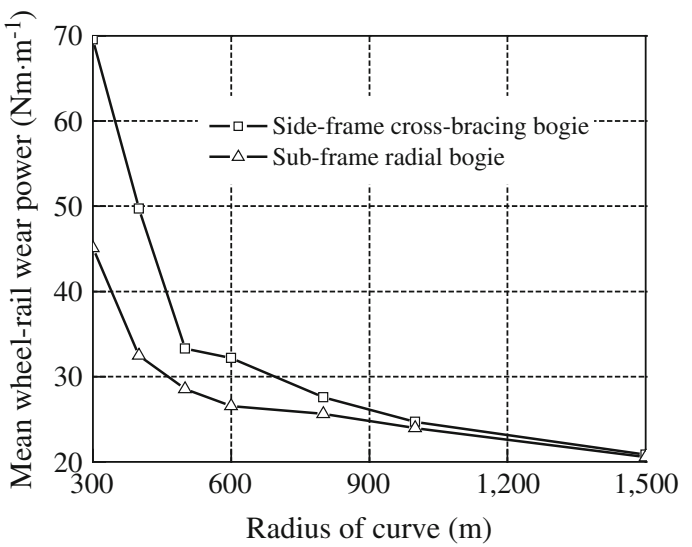

Fig. 9 Mean values of the wheel-rail dynamic interaction of the two bogies. a Wheel-rail lateral force. b Wheel-rail wear power

(a)

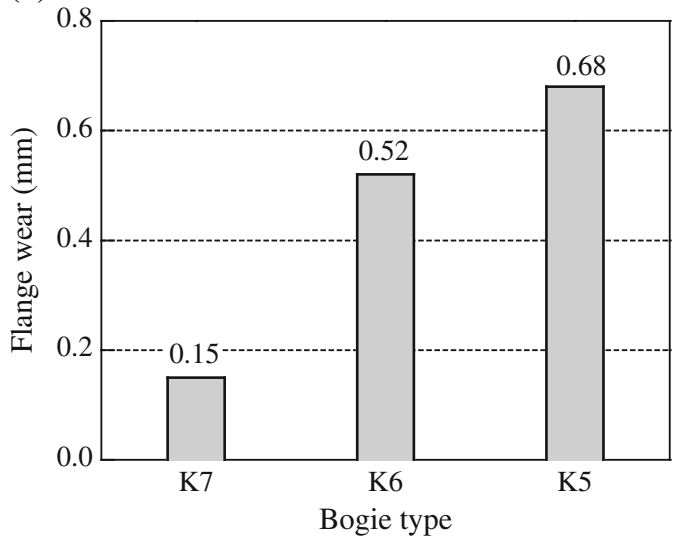

(b)

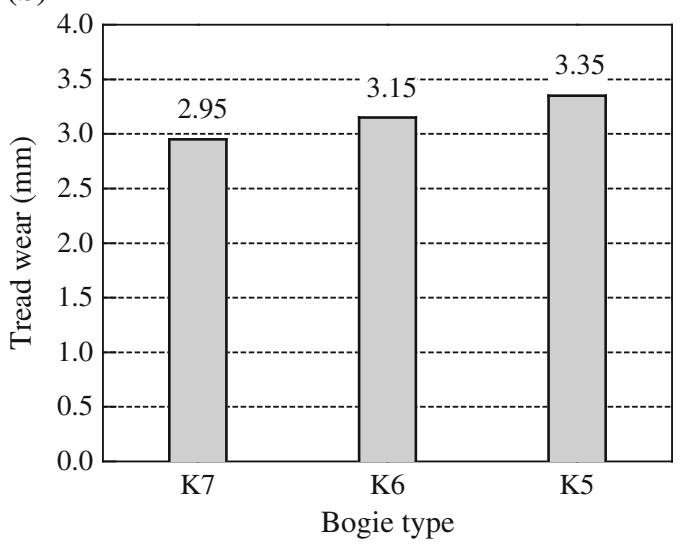

Fig. 10 Comparisons of actual flange and tread wear of different type bogies. a Mean flange wear. b Mean tread wear

mean value of tread wear of the K6-type bogie is $3.15 \mathrm{~mm}$, while that of the K7-type bogie is $2.95 \mathrm{~mm}$, also less than that of the K6-type bogie. These indicate that application of the sub-frame radial bogie would be more effective to decrease wheel-rail wear.

\section{Conclusions}

(1) Passing through the dipped rail joints, the vertical wheel-rail dynamic interaction of both the side-frame cross-bracing bogie and the sub-frame radial bogie is basically the same, but because of the heavier unsprung mass of the sub-frame radial bogie, the dynamic responses of the rail substructures are slightly larger.

(2) Running on a straight line at random excitation, the wheel-rail dynamic responses of both the bogies are basically the same with a little difference, and the running speed has almost no influence on the wheelrail vertical dynamics performance.

(3) Negotiating curves, the wheel-rail lateral force and wheel-rail wear power of the side-frame crossbracing bogie are apparently larger than those of the sub-frame radial bogie, and the smaller the curve radius, the larger the difference. Only when the curve radius is beyond $1,000 \mathrm{~m}$, the wheel-rail dynamic responses of the two bogies are basically the same. These indicate that the sub-frame radial bogie has advantages on dynamic performance, especially on curve negotiation.

Acknowledgments This work was supported by the National Natural Science Foundation of China (No. 50975238).

Open Access This article is distributed under the terms of the Creative Commons Attribution License which permits any use, distribution, and reproduction in any medium, provided the original author(s) and the source are credited. 


\section{References}

1. Mitchell JR (1982) Cross braced bogies. China Railway Sci 3(1):1-10 (in Chinese)

2. Smith RE (1992) Side-frame diagonal elastic cross braced bogies. Foreign Roll Stock (5):30-32 (in Chinese)

3. Tunna J, dos Santo GFM, Kina EJ (2009) Theoretical and service evaluation of wheel performance on frame brace trucks. In: The 9th international heavy haul conference proceedings, Shanghai, pp 409-418

4. Joly R (1988) Comparison between radial and conventional bogies. Rail Int 4:31-42

5. Scheffel H (1994) Curving and stability analysis of self-steering bogies having a variable yaw constraint. Veh Syst Dyn 23(Sup.): 425

6. Scheffel H (1997) Modifications of South Africa three-piece bogies. Foreign Roll Stock (3):34-38(in Chinese)

7. Garcia JF (2002) Theoretical comparison between different configurations of radial and conventional bogies. Foreign Roll Stock, 39(3):13-22(in Chinese)

8. Smith RE (2007) The economic/performance benefits of a steered freight car truck for heavy haul. Foreign Roll Stocks 44(1):34-37 (in Chinese)

9. Smith RE (2001) Performance comparison of a steered freight car truck and a standard three-piece truck. Foreign Roll Stock 38(6):31-35 (in Chinese)

10. Song FS, Cao ZL (2000) A report on foreign investigation into railway freight car bogies. Railway Roll Stocks 38(8):1-9 (in Chinese)

11. Zhao WH (2000) Development of the under cross-braced bogie of freight car with axle load of $25 \mathrm{t}$. Railway Roll Stocks 38(8):25-27 (in Chinese)

12. Shen G, Cao ZL, Zhao HX (2002) Analysis of effects of shape misalignment of 3-piece bogie with cross bar on dynamic performances. J Tongji Univ 30(12):1503-1507 (in Chinese)

13. Wang FD, Li Q, Miao LX (2003) Study on distribution of dynamic load on cross sustaining device for speed increased freight car bogies. J North Jiaotong Univ 27(1):28-31 (in Chinese)

14. Liu HY, Yang AG (2004) Research on the dynamics performance of K6 bogie. In Railway locomotive and car dynamic simulation conference proceedings, Chengdu, pp 265-271 (in Chinese)
15. Zhang L, Ren ZS (2004) Discussion on the influence of cross sustaining device to the dynamic character of bogie. Railway Locomot Car 24(4):50-53 (in Chinese)

16. Li LD (2008) Reliability study on the under cross-braced bogie of freight car. Dissertation, Dalian: Dalian Jiaotong University (in Chinese)

17. Cui DG, Yu LY, Lu KW (2008) Study and application of frame brace bogie technology for railway freight cars with increased speeds and higher loading capacities. J. China Railway Soc. 30(2):65-70 (in Chinese)

18. Hu HB, Xing SM, Shao WD et al (2009) Application and development of frame brace bogie of railway freight car in China. In: The 9th International heavy haul conference proceedings, Shanghai, pp 389-396

19. Zhou B, Guan Y (2010) Research on application performance of K6 bogie. In: The 3rd international conference on power electronics and intelligent transportation system, Shenzhen, China, pp 277-280

20. Li F, Fu MH, Huang YH (2002) Research of principle and dynamic characteristics of radial bogies. China Railway Sci 23(5):46-51 (in Chinese)

21. Li F, Fu MH, Huang YH (2003) Development and dynamic characteristics of radial bogies. J Traffic Transp Eng 3(1):1-6 (in Chinese)

22. Wang P (2004) Introductions of radial bogies. Railway Roll Stocks 40(4):24-25 (in Chinese)

23. Li HL (2006) Research on the dynamics and wear of truck radial bogie. Dissertation, Southwest Jiaotong University, Chengdu (in Chinese)

24. Li HL, Huang YH (2009) Research on the dynamic performance of K7 bogie. Railway Locomot Car 29(4):26-29 (in Chinese)

25. Mu FJ, Hu HT, Zeng ZX (2009) Thinking of the development of radial freight car bogies in our country. Railway Roll Stocks 47(7):9-13 (in Chinese)

26. Yang CL, Li F, Fu MH et al (2010) Dynamics analysis of $25 \mathrm{t}$ axle load steering bogie with radial arm. J. Traffic Transp Eng 10(5):1-8 (in Chinese)

27. Zhai WM (2007) Vehicle-track coupling dynamics, 3rd edn. China Railway Publishing House, Beijing (in Chinese)

28. Yang CL, Li F, Huang YH (2011) Optimization of primary vertical suspension of heavy haul freight car. J Southwest Jiaotong Univ 46(5):820-825 (in Chinese) 